University of Wollongong

Research Online

Faculty of Social Sciences - Papers (Archive) Faculty of Arts, Social Sciences \& Humanities

2012

Point-of-sale alcohol promotions in the Perth and Sydney metropolitan areas

Sandra C. Jones

University of Wollongong, sandraj@uow.edu.au

Lance Barrie

University of Wollongong, lanceb@uow.edu.au

Laura Robinson

University of Wollongong, laurar@uow.edu.au

S Allsop

Curtin University of Technology

T Chikritzhs

Curtin University of Technology

Follow this and additional works at: https://ro.uow.edu.au/sspapers

Part of the Education Commons, and the Social and Behavioral Sciences Commons

Research Online is the open access institutional repository for the University of Wollongong. For further information contact the UOW Library: research-pubs@uow.edu.au 


\title{
Point-of-sale alcohol promotions in the Perth and Sydney metropolitan areas
}

\begin{abstract}
Introduction and Aims. Point-of-sale (POS) is increasingly being used as a marketing tool for alcohol products, and there is a growing body of evidence suggesting that these materials are positively associated with drinking and contribute to creating a pro-alcohol environment. The purpose of the present study was to document the nature and extent of POS alcohol promotions in bottle shops in two Australian capital cities. Design and Methods. A purposive sample of 24 hotel bottle shops and liquor stores was selected across Sydney (New South Wales) and Perth (Western Australia) and audited for the presence and nature of POS marketing. Results. Point-of-sale promotions were found to be ubiquitous, with an average of 33 promotions per outlet. Just over half were classified as 'non-price' promotions (e.g. giveaways and competitions). Spirits were the most commonly promoted type of alcohol. The average number of standard drinks required to participate in the promotions ranged from 12 for ready to drinks to 22 for beer. Alcohol outlets that were part of supermarket chains had a higher number of promotions, more price-based promotions, and required a greater quantity of alcohol to be purchased to participate in the promotion. Discussion and Conclusions. The data collected in this study provides a starting point for our understanding of POS promotions in Australia, and poses important questions for future research in this area.
\end{abstract}

\section{Keywords}

alcohol, marketing, point-of-sale, Australia, pricing

Disciplines

Education | Social and Behavioral Sciences

\section{Publication Details}

Jones, S. C., Barrie, L., Robinson, L., Allsop, S. \& Chikritzhs, T. (2012). Point-of-sale alcohol promotions in the Perth and Sydney metropolitan areas. Drug and Alcohol Review, 31 (6), 803-808. 


\title{
Point-of-sale alcohol promotions in the Perth and Sydney metropolitan areas
}

\author{
Sandra C. Jones, Centre for Health Initiatives, University of Wollongong \\ Lance Barrie, Centre for Health Initiatives, University of Wollongong
}

\begin{abstract}
There is considerable evidence that reducing the price of alcohol increases the amount consumed, particularly among young people. However, there is an absence of research on other point-of-sale (POS) alcohol marketing strategies - such as those that 'reward' purchasers with free gifts. The purpose of the present study was to document the nature and extent of POS alcohol promotions in bottle shops in two Australian capital cities. An audit tool was developed and point-of-sale promotions were found to be ubiquitous, with 416 promotions identified across 24 audits (an average of 17.3 promotions per outlet; 19.8 in Sydney and 14.9 in Perth). The most concerning finding was that these promotions appear to provide an incentive for (young) consumers to increase their purchase quantity.
\end{abstract}

NOTE: This project was funded by an ARC Linkage Grant, in partnership with the Department of Communities in Western Australia

The authors acknowledge the contribution of co-investigators Prof Steve Allsop and A/Prof Tanya Chikritzhs of the National Drug Research Institute, Curtin University 


\section{Point-of-sale alcohol promotions in the Perth and Sydney metropolitan areas}

\section{Introduction}

Excessive alcohol consumption is a major public health issue for Australia, the US, the UK and most other industrialized countries. As well as the obvious long-term risks associated high levels of alcohol consumption, binge-drinking is associated with a range of short-term risks including alcohol poisoning, unsafe sex, sexual assault, physical violence, motor vehicle accidents, property damage and other criminal activities (Perkins and Wesley, 2002; Wechsler et al., 1995; Wechsler et al., 1994). The National Alcohol Indicators Project (NAIP) has estimated that between 1993 and 2002, over 2,500 young people aged between 15 and 24 years died from alcohol-attributable injury and disease and more than 100,000 were hospitalized (Chikritzhs et al., 2004).

Recent Australian research has found that alcohol is widely used by secondary students, with 50\% of 16-17 year olds surveyed having consumed alcohol in the week prior to the survey, and 35\% having consumed at dangerous levels (White et al., 2003). This continues into young adulthood, with the 2004 National Drug Strategy Household Survey finding that approximately $64.7 \%$ of males and $57.2 \%$ of females aged between 20 and 29 years consumed alcohol at risky or high-risk levels (seven or more alcoholic beverages on at least one occasion for males, five or more for females) in the 12 months prior to the survey, and $17.4 \%$ of males and $10.9 \%$ of females consumed this amount at least weekly during the same 12 month period (AIHW, 2005).

\section{Alcohol point-of-sale promotions}

In recent years alcohol advertising has come under scrutiny from both researchers and policy makers, resulting in efforts to improve the regulation of advertising practices. The potential influence of mass media - and particularly advertising - on the alcohol-related attitudes and behaviours of young people has been widely recognised. The promotion of alcohol by retailers and media can contribute to the creation of a culture in which excessive alcohol consumption is seen as the norm. There is considerable evidence that increased availability of alcohol is associated with increased alcohol consumption; that there is an inverse relationship between the price of alcohol and the level of consumption (Coate and Grossman, 1988; Osterberg, 1995; Levy and Sheflin, 1983); and that this effect is even more pronounced among young people (Chaloupka and Weschler, 1996; Kenkel, 1993; Sutton and Godfrey, 1995). For example, a study of the effect of promotions on US university students (Kuo et al., 2003) found that for off-premise outlets (e.g. bottle shops) higher binge-drinking rates were corrrelated with: the availability of large volumes of beer; lower average price of a carton of beer; interior and exterior advertising; and promotions such as volume discounts, advertised price specials, or coupons.

Point-of-sale (POS) refers to promotional materials that are found within a store or venue, at the point where a purchase will be made. This differs from more traditional media 
channels that capture the audience's attention at a time when they have no direct opportunity to purchase. This form of promotion is of increasing importance to many marketers, with U.S companies alone spending an estimated $\$ 17$ billion on promoting their products within supermarkets and other stores (Belch and Belch, 2001). Point-of-sale promotions have been shown to encourage product trial and increase purchase volume (Gilpin et al., 1997). A UK study found that young people's smoking status was associated with tobacco point of sales marketing, such as gifts with purchases and special price offers (MacFadyen et al., 2001). Australian research on tobacco point-of-sale has shown that adolescents exposed to this form of marketing have higher recall of cigarette brands, and weaker intentions not to smoke (Wakefield et al., 2006); and report more positive brand user imagery - such as describing the typical user as interesting, relaxed, adventurous and cool (Donovan et al., 2002).

POS is increasingly being used as a marketing tool for alcohol products, to the point where it is has been coined as "aggressive" (Howard et al., 2004); with the alcohol industry becoming increasingly competitive, marketers are turning to POS promotions to appeal to a captive audience. These marketers are exploiting activities such as providing price promotions, gift-with-purchase incentives, as well as bulk-purchase incentives, all of which can be seen as encouraging sales figures rather than brand loyalty or development. There is a growing body of evidence suggesting that these point-of-purchase materials are positively associated with drinking and contribute to creating a pro-alcohol environment (Howard et al., 2004). A US study of POS promotions across a range of store types in 2000-2001 found that the majority of stores (94\%) had some form of POS alcohol marketing, and 44\% of stores had low-height (and thus visible to children) interior alcohol advertising; (TerryMcElrath et al., 2003). A US study found that young people (mid-adolescents, grades 7 and 9) with higher levels of exposure to in-store beer displays and promotions were more likely to be drinking by grade nine (Ellickson et al., 2005), although this could be confounded by other factors which increase the likelihood of both exposure and consumption.

In Australia, the sale of alcohol for on-premise consumption is covered by rules that are designed to prevent practices that encourage excessive consumption. For example, the industry's Alcohol Beverages Advertising (And Packaging) Code states that "Promotional staff at events do not promote consumption patterns that are inconsistent with responsible consumption, as defined in the NHMRC Guidelines"; and the NSW Office of Liquor Gaming and Racing's Liquor Promotion Guidelines (2009) prohibit promotions that "encourage irresponsible, rapid or excessive consumption of liquor" including, specifically, "two for the price of one offers". However, such rules do not currently extend to offpremise (bottleshop) sales. The purpose of the present study was to document the nature and extent of POS alcohol promotions in bottleshops in two Australian capital cities.

\section{Method}

Based on the evidence and practice of the only published POS alcohol research conducted in Australia (Jones and Lynch, 2007) and research conducted by the Centre for Health 
Initiatives in 2007 for NSW Health (Jones et al., confidential report to NSW Health); a draft audit tool was developed to identify the nature of promotions (location, size, dominance), details of the promotional products (e.g. quantity and/or alcohol percentage required to purchase to receive promotion); and the type of promotions typically used by alcohol companies. Promotions were defined as any activity initiated by the manufacturer or retailer which aims to develop and maintain brand awareness and/or to influence purchasing intentions (e.g. price promotions, competitions, gift promotions, and percentage discounts on bulk sales). This approach is based on techniques used in tobacco point of sale research (Jalleh et al., 2005) and recent alcohol research (Smith et al., 2005).

The target venues were hotel bottle shops and liquor stores. A purposive sample was selected across Sydney (New South Wales) and Perth (Western Australia) to include a representative mix of independently owned and run stores, national liquor chain group member stores (e.g., Cellarbrations, Liquor Barons, Bottlemart, the Bottle-O) and alcohol outlets connected with large supermarket chain (e.g., BWS, Liquorland, First Choice etc). Where possible, advertisements in local print media were reviewed to identify hotel and liquor store advertisements two - three weeks before the data are to be collected (bottle shops and liquor stores regularly advertise in this manner). Bottleshops were selected across a range of major metropolitan areas in Sydney and Perth (i.e., north, south east, west) and, where possible, were located within a close vicinity of large shopping centres (Smith et al., 2005). This type of purposive sampling does not result in a fully representative sample of all off-premise outlets. The procedure does, however, identify the larger consortia of liquor outlets and allows description of the nature of alcohol promotions in a range of outlets in different geographical locations. After suitable liquor outlets had been identified, the project officer formally contacted (by letter or by phone) the Licensee/manager and described the purpose and nature of the research and gained consent to undertake the audit. Outlets were able to refuse participation at this initial stage and were not identified in the reporting of data. A moderate rejection rate was anticipated (30\%) however previous studies have demonstrated high willingness to participate among licensees (Smith et al., 2005).

In each city, auditors were trained to use the audit tool and were given an information sheet about the project and a script to use when speaking to bottleshop owners/licensees about the project, and to respond to questions from customers if they made any enquiries as to the nature and purpose of the audit. When entering the bottleshop, auditors identified themselves to the manager as researchers from the University of Wollongong/Curtin University and provided evidence of permission granted to complete the audit and/or sought permission from the manager at the time of the audit). All audit staff worked in pairs. Each auditor conducted an independent audit and upon completion, the two auditors compared their findings and verbally discussed any discrepancies before jointly compiling a report using the specified format. Data from the audit tool were entered into the statistical software package, SPSS (Version 17.0). Simple frequencies and descriptive statistics form the basis of analysis which focuses on the nature and variety of POS promotions and the types of advertising or marketing strategies used. 


\section{Results}

The rejection rate from stores approached was $24.5 \%$ (slightly lower than anticipated); $25.9 \%$ in Sydney and $23.1 \%$ in Perth. Point-of-sale promotions were found to be ubiquitous, with 416 promotions identified across 24 audits (an average of 17.3 promotions per outlet; 19.8 in Sydney and 14.9 in Perth). A total of 175 different promotions were identified in Sydney and Perth. Table 1 shows the type of promotion identified in Sydney and Perth.

Table 1: Average number of promotions per outlet and types of promotions

\begin{tabular}{cccc}
\hline Type of Promotion & Sydney & Perth & Overall \\
Competition & $49 \%$ & $56 \%$ & $53 \%$ \\
Free Gifts & $26 \%$ & $28 \%$ & $27 \%$ \\
Other & $25 \%$ & $16 \%$ & $20 \%$ \\
\hline
\end{tabular}

Most promotions were attached to spirit or liqueur products $(n=73)$ or to wines $(n=56)$, followed by beer $(n=36)$ and RTD's $(n=19)$. In several instances, the same promotion was seen on both a RTD and a spirit of the same brand, which is why the total number of promotions $(n=184)$ differs from the number of unique promotions identified $(n=175)$.

The vast majority of unique promotions (97\%) required the purchase of more than four standard drinks to participate; with total standard drinks ranging from 1.4 to 92.4 , with an average of 19.3 per promotion. Table 2 shows the total number of promotions of each type, and the average number of standard drinks required to participate in the promotions, across each of the three store types.

Table 2: Total number of promotions by store type

\begin{tabular}{lccc}
\hline & \multicolumn{3}{c}{ Type of Store } \\
\hline Type of Promotion & $\begin{array}{c}\text { Independent } \\
\text { store }\end{array}$ & $\begin{array}{c}\text { Liquor } \\
\text { Chain }\end{array}$ & $\begin{array}{c}\text { Supermarket } \\
\text { Chain }\end{array}$ \\
Competitions & 42 & 97 & 83 \\
Free gift & 24 & 53 & 35 \\
Get some alcohol free & 2 & 4 & 2 \\
Discounted price & 1 & 0 & 0 \\
Gift pack & 2 & 14 & 37 \\
other & 3 & 8 & 7 \\
Total & $\mathbf{7 4}$ & $\mathbf{1 7 6}$ & $\mathbf{1 6 4}$ \\
\hline & & & \\
\hline Type of alcohol & & & \\
Beer or cider & 19 & 37 & 49 \\
Spirits or liqueur & 20 & 68 & 77 \\
Wine or any purchase & 21 & 48 & 12 \\
RTD & 14 & 23 & 26 \\
Total & 74 & 176 & 164 \\
\hline & & & \\
\hline Average Standard drinks per promotion & $\mathbf{2 0 . 1}$ & $\mathbf{1 9 . 2}$ & $\mathbf{1 9 . 0}$ \\
\hline
\end{tabular}




\section{Discussion}

As noted in the introduction, there is a virtual absence of research into (non-price) point-ofsale alcohol marketing, particularly in the Australian context (although we can draw some parallels to tobacco POS marketing, which has been more extensively researched). Thus, the data collected in this study provides a starting point for our understanding of this type of promotion in Australia, and poses important questions for future research in this area. Our audit of 24 alcohol outlets in metropolitan Sydney and Perth identified 416 POS promotions (excluding simple price reductions), an average of 17.3 per outlet. We note that this was substantially higher than the average of 10 promotions per outlet found in a 2008 study of bottleshops in metropolitan, regional and rural areas of New South Wales (Jones et al., confidential report to NSW Health). Importantly, the rate of promotions in urban areas was lower than in rural and remote areas (mean of 7.7 across the 23 Sydney audits; lowest in the Sydney CBD, with an average of 4.8 across the six audits). This suggests that the frequency of promotions has increased over time.

Competitions were the most frequently identified type of promotion, accounting for over $50 \%$ of the total, consistent with the 2008 NSW data. A total of 175 different promotions were identified in Sydney and Perth. Free gifts with alcohol purchase accounted for over a quarter of identified POS promotions, which is particularly concerning given the strong evidence from the United States of an association between adolescents' ownership of alcohol-branded merchandise and future drinking (Henriksen et al., 2006; McClure et al., 2006). While alcohol is sold in bottleshops only to people over the age of 18 , and thus it could be argued that the merchandise is targeted to those over the legal drinking age, qualitative research with young people shows that they are frequently the final recipients of such materials and that this is associated with positive brand associations (Jones et al., confidential report to NSW Health). Further, free gift promotions were most commonly associated with the product types consumed by young drinkers (that is beer and RTDs).

However, the most concerning finding was that participation in POS promotions almost universally required the purchase of a large number of standard drinks, on average just under 19 per promotion. The linking of desirable items to the purchase of multiple units of alcohol, particularly given existing pricing strategies which often result in it being (for example) cheaper to purchase six RTDs than four of the identical product (Jones and Barrie, 2010), has clear potential to increase the amount of alcohol purchased and, in many cases, consumed on a single occasion.

There is a need for further research to investigate the effects of such promotions on purchase, and consumption, volumes (particularly among younger drinkers). However, we argue that there is also a need to consider the regulation of such promotions, perhaps by expanding the remit of existing codes - or, ideally, for marketers to consider modifying the nature of point-of-sale alcohol promotions - to reduce the impact of marketing activities on alcohol-related harms. Based on this data, the most immediate recommendation for policy and practice would be restrictions on the use of promotions that require the purchase of large volumes of alcohol to obtain a free gift or enter a competition. 


\section{References}

AIHW, 2005. 2004 National drug strategy household survey. Drug statistics series, number 13. Canberra.

Babor, T.F., Mendelson, J.H., Greenberg, I., Kuehnle, J., 1978. Experimental analysis of the 'happy hour'. Psychopharmacology 58, 35-41.

Belch, G., Belch, M., 2001. Advertising and promotion. $5^{\text {th }}$ ed. McGraw-Hill Irwin, New York.

Chaloupka, F.J., Weschler, H., 1996. Binge drinking in college: the impact of price, availability, and alcohol control policies. Contemporary Economic Policy 14(4), 112-124.

Chikritzhs, T., Pascal, R., Jones, P., 2004. Under-aged drinking and related harms in Australia. National Alcohol Indicators, Bulletin No.7. Perth: National Drug Research Institute, Curtin University.

Donovan, R.J., Jancey, J. and Jones, S.C. (2002). "Tobacco point of sale advertising increases positive brand user imagery. (Research Paper).(Statistical Data Included)." Tobacco Control 11(3): 191(4).

Ellickson, P.L., et al., 2005. Does alcohol advertising promote adolescents drinking? Addiction 100, 235-246.

Gilpin, E., et al., 1997. Are adolescents receptive to current sales promotion practices of the tobacco industry? Preventive Medicine 26, 14-21.

Henriksen, L., Feighery, E. C., Schleicher, N.C., Fortmann, S.P., 2008. Receptivity to alcohol marketing predicts initiation of alcohol use. Journal of Adolescent Health 42(1), 2835 .

Howard, K.M., Flora, J.A., Schleicher, N.C., Gonzalez, E.M., 2004. Alcohol point-ofpurchase advertising promotions. Contemporary Drug Problems 31(3), 561-583.

Jalleh, G., Donovan, R.J., Stewart, S., Sullivan, D., 2005. Selling or promotion? Tobacco Control 14, 430.

Jones, S.C., Barrie, L., 2010. RTDs in Australia: expensive designer drinks or cheap rocket fuel? Drug \& Alcohol Review (online ahead of print).

Jones, S.C., Lynch, M., 2007. A pilot study investigating of the nature of point-of-sale alcohol promotions in bottle shops in a large Australian regional city. Australian and New Zealand Journal of Public Health 31(4), 318-321. 
Kenkel, D., 1993. Driving, driving and deterrence: the effectiveness and social costs of alternative policies. Journal of Law and Economics., 36: 877-913. In: Babor, T., Caetano, R., Casswell, S., Edwards, G., Giesbrecht, N., Graham, K., Grube, J., Grunewald, P., Hill, L., Holder, H., Homel, R., Osterberg, E., Rehm, J., Room, R., Rossow, I., Alcohol: No ordinary commodity, research and public policy. Oxford University Press, New York.

Kuo, M., Wechsler, H., Greenberg, P., Lee, H., 2003. The marketing of alcohol to college students. American Journal of Preventive Medicine 25(3), 204-211.

MacFadyen, L., Hastings, G., MacKintosh, A.M., 2001. Cross sectional study of young people's awareness and involvement with tobacco marketing. British Medical Journal 322(7285), 513-517.

McClure, A.C., Dal Cin, S., Gibson, J. and Sargent, J.D., 2006. Ownership of alcoholbranded merchandise and initiation of teen drinking. American Journal of Preventive Medicine 30(4), 277-283.

Perkins, H.W., 2002. Social norms and prevention of alcohol misuse in college contexts. Journal of Studies on Alcohol 14, 164-172.

Smith, A., Edwards, C., Harris, W., 2005. Bottleshops and 'ready-to-drink' alcoholic beverages. Health Promotion Journal of Australia 16, 32-36.

Sutton, M., Godfrey, C., 1995. A grouped data regression approach to estimating economic and social influences on individual drinking behaviour. Health Economics 4, 237-247.

Terry-McElrath, Y.M., Harwood, E.M., Wagenaar, A.C., Slater, S., Brewer, R.D., Naimi, T.S., 2003. Point-of-Purchase Alcohol Marketing and Promotion by Store Type - United States, 2000-2001. MMWR Weekly 52(14), 310-313.

Wakefield, M., Germain, D., Durkin, S. and Henriksen, L. (2006). "An experimental study of effects on school children's exposure to point-of-sale cigarette advertising and pack displays." Health Education Research Theory \& Practice 21(3): 338-347.

Wechsler, H., Davenport, A., Dowdall, G., Moeykens, B., Castillo, S., 1994. Health \& behavioural consequences of binge drinking in college: a national survey of students at 140 campuses. Journal of the American Medical Association 272(21), 1672-1677.

Weschler, H., Moeykens, B., Davenport, A., Castillo, S., Hansen, J., 1995. The adverse impact of heavy episodic drinkers on other college students. Journal of Studies on Alcohol 56(6), 628-634. 
White, V.M., Hill, D.J., Effendi, Y., 2003. Patterns of alcohol use among Australian secondary students: Results of a 1999 prevalence study and comparisons with earlier years. Journal of Studies on Alcohol 64(1), 15-22. 